\title{
IMPROVEMENT OF DISSOLUTION RATE OF VALSARTAN BY SOLID DISPERSION SYSTEM USING D(-) MANNITOL
}

ERIZAL ZAINI*, SALMAN UMAR, NURHIDAYAH FIRDAUS

Department of Pharmaceutics, Faculty of Pharmacy, Andalas University, Kampus Limau Manis, Padang, Indonesia. Email: erizal.ffua@gmail.com

Received: 14 November 2016, Revised and Accepted: 05 December 2016

\section{ABSTRACT}

Objective: To improve dissolution rate of valsartan from solid dispersion system of valsartan and D(-) mannitol using co-grinding approach.

Methods: Valsartan solid dispersion with different ratio of $\mathrm{D}(-)$ mannitol $(1: 1 ; 1: 3$ and $1: 5)$ were prepared by co-grinding method. Solid state characterization of the solid dispersion system was evaluated in term of crystallographic properties (powder X-ray diffraction), thermal behavior (differential scanning calorimetry [DSC]) and morphology (scanning electron microscope). The profile of dissolution rate was examined using USP dissolution apparatus type I at a temperature of $37 \pm 0.5^{\circ} \mathrm{C}$

Results: Based on thermal analysis DSC and powder X-ray diffraction analysis, valsartan was transformed from semicrystalline phase to amorphous state as indicated by the disappearance of its melting endothermic peaks and the characteristic diffraction peaks. The in vitro dissolution rate study revealed that all solid dispersion system showed significant increase in dissolution rate compared with the intact valsartan.

Conclusion: Solid dispersion of valsartan with $\mathrm{D}(-)$ mannitol prepared by co-grinding technique has successfully improved the dissolution rate compared with intact valsartan.

Keywords: Valsartan, D(-) mannitol, Solid dispersion, Co-grinding, Dissolution rate.

(C) 2017 The Authors. Published by Innovare Academic Sciences Pvt Ltd. This is an open access article under the CC BY license (http://creativecommons. org/licenses/by/4. 0/) DOI: http://dx.doi.org/10.22159/ajpcr.2017.v10i3.16171

\section{INTRODUCTION}

Optimization of the physicochemical properties of a drug molecule is important in the development of solid oral dosage forms. The solid state properties of a drug compound such as the crystalline phase, amorphous, pseudopolymorph and salt will significantly affect the dissolution rate and bioavailability of drug compounds in the systemic circulation. For poorly soluble drugs, in particular, the dissolution process is a rate limiting step for absorption in the gastrointestinal tracts [1]. Some of current approaches have been proposed to improve the dissolution rate and bioavailability of drug compounds including the formation of inclusion complexes with $\beta$-cyclodextrin [2], the formation of eutectic mixture and cocrystalline phase [3,4], nanoparticle formulation [5], and amorphous solid dispersion system [6].

Valsartan is one of poorly soluble drugs, an orally active angiotensin II receptor antagonist. It has been used to lower the blood pressure in hypertensive patients. Valsartan is classified as Class II compound according to the biopharmaceutical classification system with high permeability but low aqueous solubility with a dissolution rate dependent absorption [7]. The gastrointestinal absorption of valsartan can be enhanced by increasing its dissolution rate. Several methods have been proven effective to improve dissolution rate of valsartan including formation of self-microemulsifying system [7], nanosuspension [8], formation of mucoadhesive pellets [9], and inclusion complexes with $\beta$-cyclodextrin [2]. One attractive approach to increase the dissolution rate is formation of solid dispersion of poorly soluble drugs with some carriers such as PVP K-30, HPMC, and $D(-)$ mannitol. Solid dispersion can be defined as dispersion of active pharmaceutical ingredients in inert carriers or matrix in solid state. It can be prepared by solvent, melting and co-grinding method [10-12].
The aim of this study was to prepare and characterize solid dispersion system of valsartan and D(-) mannitol using co-grinding approach, and to investigate the mechanisms responsible for the improved dissolution rate of valsartan from solid dispersion system.

\section{MATERIALS AND METHODS}

\section{Materials}

Valsartan was purchased from Baoji Guokang Bio Technology CO., Ltd (China). D(-)-Mannitol was obtained from Merck (Germany). All other chemicals and solvents were of analytical grade.

\section{Methods}

Preparation of solid dispersion

Solid dispersion system of valsartan - D(-) mannitol at various weight ratios $(1: 1,1: 3$, and $1: 5)$ were prepared by co-grinding technique. The binary mixtures were ground in planetary ball milling apparatus (FRITSCH, pulverissete 7, Germany) for 120 minutes at $500 \mathrm{rpm}$. Coground products were kept in a desiccator until further characterization.

\section{X-ray powder diffraction analysis (XRPD)}

XRP diffractograms were recorded using X-ray diffractometer (PAN Analytical The Netherlands). Samples were exposed to $\mathrm{Cu}-\mathrm{K} \alpha$ radiation source at $40 \mathrm{kV}$ and $12 \mathrm{~mA}$. The diffraction patterns were obtained in $2 \theta$ range of $10-40^{\circ}$.

\section{Differential scanning calorimetry (DSC) analysis}

The thermal analysis was performed using TA Mettler Toledo FP90 DSC (Switzerland). Samples of solid dispersion and intact valsartan were weighed approximately 1-2 $\mathrm{mg}$ in aluminum pan. The heating was set from 50 to $250^{\circ} \mathrm{C}$ at a heating rate of $10^{\circ} \mathrm{C} /$ minute. 
Scanning electron microscopy (SEM) analysis

Crystal habit observation of samples was conducted using scanning electron microscope (HITACHI type S-3400N, Japan). The voltage and current were set at $10 \mathrm{kV}$ and $12 \mathrm{~mA}$, respectively. All samples were sputter-coated with a thin gold palladium layer before analysis.

\section{In vitro dissolution rate study}

In vitro dissolution rate study was conducted using USP dissolution apparatus type I (Hanson research SR08, USA) at a temperature

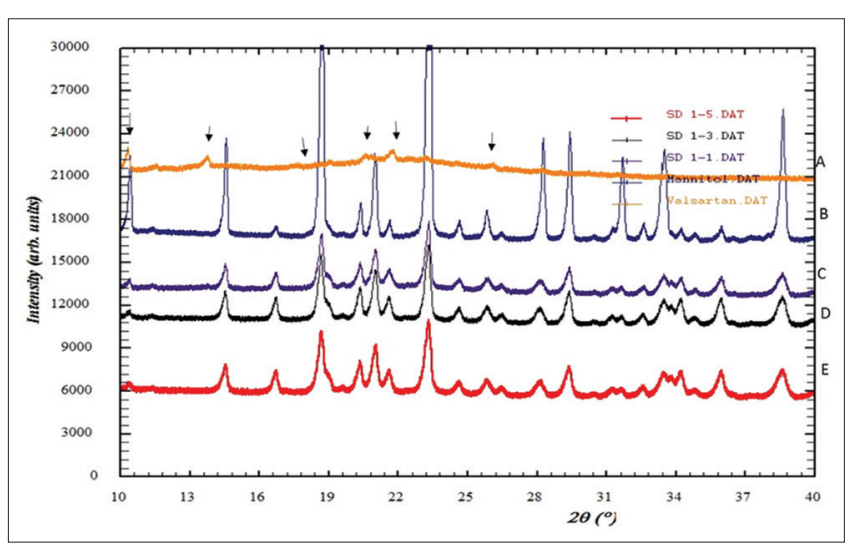

Fig. 1: X-ray powder diffraction pattern of (a) intact valsartan, (b) D(-) mannitol, (c) solid dispersion 1:1, (d) solid dispersion $1: 3$, and (e) solid dispersion 1:5

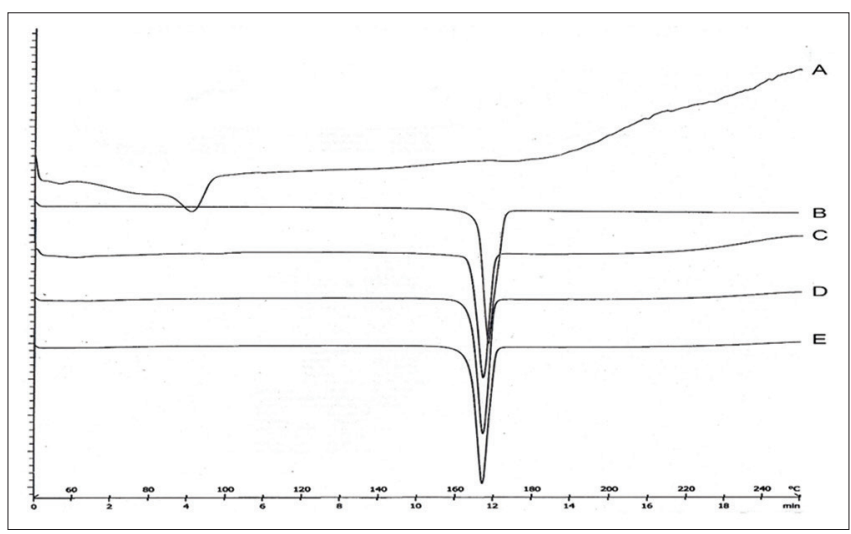

Fig. 2: Differential scanning calorimetry thermogram of (a) intact valsartan, (b) D(-) mannitol, (c) solid dispersion 1:1, (d) solid dispersion 1:3, and (e) solid dispersion 1:5 of $37 \pm 0.5^{\circ} \mathrm{C}$ and a stirring rate of $50 \mathrm{rpm}$. The dissolution media was $900 \mathrm{~mL}$ of aqueous phosphate buffer solution (pH 6.8). $5 \mathrm{~mL}$ of aliquot were withdrawn at designated time intervals $(5,15,30$, 45 , and 60 minutes), filtered and analyzed by ultraviolet-visible spectrophotometer (Shimadzu UV-1700, Japan) at $\lambda_{\max } 250.4 \mathrm{~nm}$. The experiment was performed in triplicate.

\section{RESULTS AND DISCUSSION}

XRPD method is most commonly used to investigate the solid state properties of any solid active pharmaceutical ingredients materials [3]. In this study, XRPD measurement was performed for each raw materials and solid dispersion samples. XRP diffractograms of intact valsartan and solid dispersions with D-mannitol are shown in Fig. 1. The presence of numerous characteristic peaks in the XRP diffractogram of valsartan in low intensity indicates that valsartan is in semicrystalline state with characteristic peaks appearing at a diffraction angle of $2 \theta$ at 10.20 , 11.47, 13.69, 20.49, 21.76, 23.17, 26.06 (Fig. 1a). Meanwhile, D(-) mannitol is present as a high crystalline in nature with characteristic peaks appearing at a diffraction angle of $2 \theta$ at $10.41,14.58,18.66$, 20.28, 20.91, 23.34, 28.10, 29.37, 31.67, 33.54, 38.56 (Fig. 1b). After preparation of solid dispersion by co-grinding with $\mathrm{D}(-)$ mannitol, characteristic peaks of valsartan were disappeared, only characteristic peaks of D-mannitol were exist (Fig. 1c-e). This indicated that the semicrystalline phase of valsartan was transformed to amorphous state.

Thermal analysis of DSC was performed on intact valsartan, D(-) mannitol, and solid dispersion system to investigate the interaction between valsartan and D(-) mannitol in the solid state [3]. The DSC thermogram of intact valsartan shows a single endothermic peak at $91.07^{\circ} \mathrm{C}$, due to the melting of the drug. The DSC thermogram of D(-) mannitol exhibited a single sharp melting endothermic peak at $166.35^{\circ} \mathrm{C}$ (Fig. 2a and b). The characteristic endothermic peak of valsartan disappeared in all thermograms of solid dispersion system (Fig. 2c-e). Thus, the semicrystalline drug was embedded in the hydrophilic carrier and its solid state properties changed to amorphous one [10]. Previous studies have reported that disappearance of the characteristic endothermic peaks of the valsartan dispersed in Gelucire 50/13 is due to melting of the drug in the matrix [13].

SEM analysis was performed to observe the surface and crystal habit of different samples (intact valsartan, D(-) mannitol and solid dispersions system). SEM of the raw materials revealed that valsartan was characterized by irregular shaped crystals, whereas $\mathrm{D}(-)$ mannitol formed big polyhedral shape particles (Fig. 3a and b). Solid dispersions prepared by co-grinding technique represented a reduction of particles size of these binary mixtures (Fig. 3c-e).

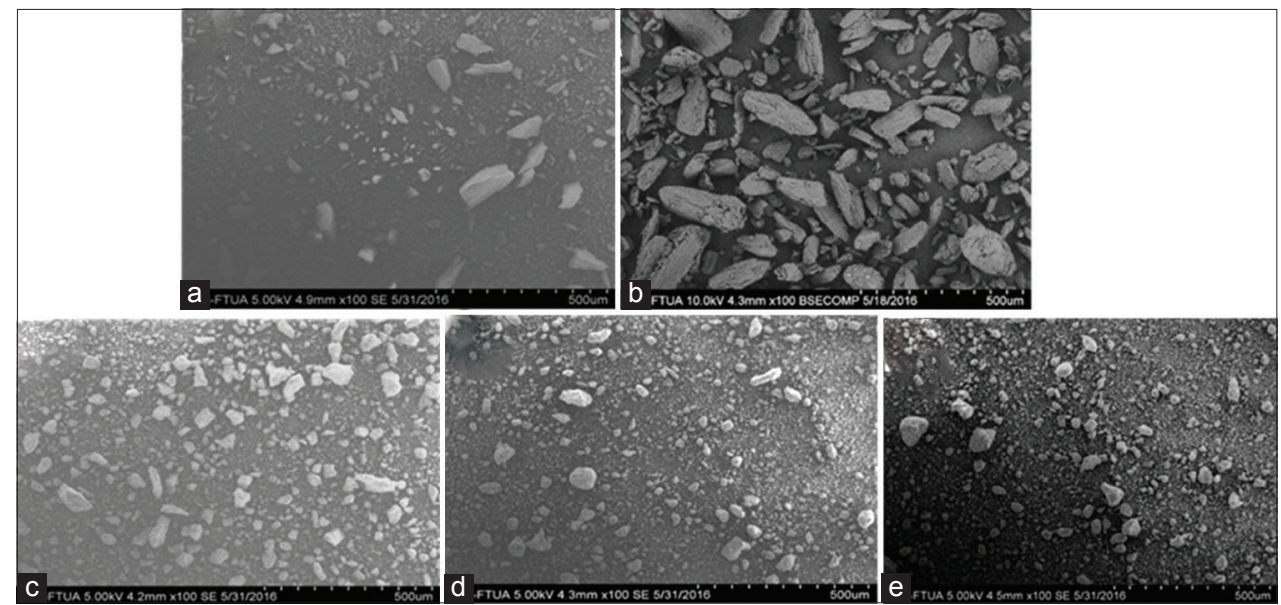

Fig. 3: Scanning electron micrographs of (a) intact valsartan, (b) D(-) mannitol, (c) solid dispersion 1:1, (d) solid dispersion 1:3, and (e) solid dispersion 1:5. All micrographs were taken at a magnification of $\times 100$ 


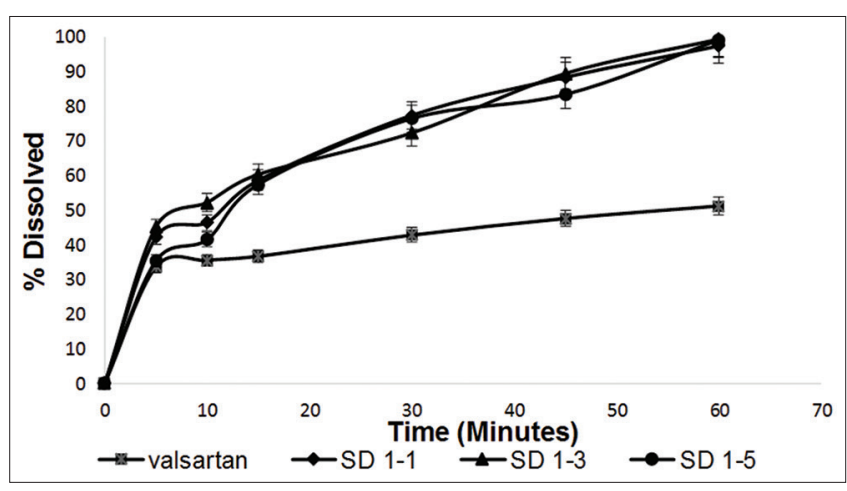

Fig. 4: Dissolution rate profile of intact valsartan and solid dispersion system prepared by co-grinding method

This indicated that cogrinding process may decrease particle size of valsartan in this system.

Dissolution rate profile of intact valsartan and solid dispersions are shown in Fig. 4. It is obvious from the figure that all solid dispersions of valsartan showed superior dissolution rate compared with intact valsartan. Solid dispersions of valsartan with $\mathrm{D}(-)$ mannitol in different ratios $(1: 1,1: 3$, and 1:5) showed a marked enhancement in the drug dissolution rate, in which about $88.45 \%, 89.52$, and $83.47 \%$ of the incorporated valsartan was dissolved within the first 45 minutes from solid dispersions, respectively. Valsartan as a poorly water soluble drug was embedded in the crystal lattice of $\mathrm{D}(-)$ mannitol during co-grinding process in the planetary ball mill apparatus. This strategy is a simple way to enhance the drug dissolution. The similar results have been reported for ketoprofen solid dispersion powders prepared with D(-) mannitol and PVP K-30 [14]. The solid state of valsartan in the carriers was in amorphous form and dispersed homogeneously as fine particles. Mechanisms suggested to be responsible for the increased dissolution rate of valsartan in solid dispersion system include reduction of particle size of valsartan, amorphization, and improved wettability of valsartan by hydrophilic carrier at diffusion layer $[15,16]$.

\section{CONCLUSION}

This study clearly shows that solid dispersion of valsartan with $\mathrm{D}(-)$ mannitol prepared by co-grinding technique has successfully improved the dissolution rate compared with intact valsartan. Co-grinding process may cause a phase transformation of the semicrystalline form to the amorphous state.

\section{ACKNOWLEGMENTS}

The authors would like to thank Faculty of Pharmacy, Andalas University for research grants.

\section{REFERENCES}

1. Hörter D, Dressman JB. Influence of physicochemical properties on dissolution of drugs in the gastrointestinal tract. Adv Drug Del Rev 2001;46(1):75-87.

2. Chadha R, Bala M, Arora P, Jain DV, Pissurlenkar RR, Coutinho EC. Valsartan inclusion by methyl- $\beta$-cyclodextrin: Thermodynamics, molecular modelling, Tween 80 effect and evaluation. Carbohydr Polym 2014;103:300-9.

3. Zaini E, Wahyuni YS, Halim A, Yuliandra Y. Preparation of eutectic mixture of ketoprofen and nicotinamide for enhanced dissolution rate. Int J Pharm Sci Rev Res 2015;35(1):161-4.

4. Alatas F, Ratih H, Soewandhi SN. Enhancement of solubility and dissolution rate of telmisartan by telmisartan-oxalic acid co-crystal formation. Int J Pharm Pharm Sci 2015;7(3):423-6.

5. Ojha S, Kumar B. Formulation and optimization of chitosan nanoparticles of dimethyl fumarate using box-Behnken design. Int J Appl Pharm 2016;8(4):10-7.

6. Fitriani L, Haqi A, Zaini E. Preparation and characterization of solid dispersion freeze-dried efavirenz-polyvinylpyrrolidone K-30. J Adv Pharm Tech Res 2016;7(3):105-9.

7. Beg S, Swain S, Singh HP, Patra CN, Rao MB. Development, optimization, and characterization of solid self-nanoemulsifying drug delivery systems of valsartan using porous carriers. AAPS PharmSciTech 2012;13(4):1416-27.

8. Ma Q, Sun H, Che E, Zheng X, Jiang T, Sun C, et al. Uniform nano-sized valsartan for dissolution and bioavailability enhancement: Influence of particle size and crystalline state. Int J Pharm 2013;441(1):75-81.

9. Cao QR, Liu Y, Xu WJ, Lee BJ, Yang M, Cui JH. Enhanced oral bioavailability of novel mucoadhesive pellets containing valsartan prepared by a dry powder-coating technique. Int J Pharm 2012;434(1):325-33.

10. Muehlenfeld C, Kann B, Windbergs M, Thommes M. Solid dispersions prepared by continuous cogrinding in an air jet mill. J Pharm Sci 2013;102(11):4132-9.

11. Kim EJ, Chun MK, Jang JS, Lee IH, Lee KR, Choi HK. Preparation of a solid dispersion of felodipine using a solvent wetting method. Eur J Pharm Biopharm 2006;64(2):200-5.

12. Zajc N, Obreza A, Bele M, Srčič S. Physical properties and dissolution behaviour of nifedipine/mannitol solid dispersions prepared by hot melt method. Int J Pharm 2005;291(1):51-8.

13. Shrivastava AR, Ursekar B, Kapadia CJ. Design, optimization, preparation and evaluation of dispersion granules of valsartan and formulation into tablets. Curr Drug Deliv 2009;6(1):28-37.

14. Yadav PS, Kumar V, Singh UP, Bhat HR, Mazumder B. Physicochemical characterization and in vitro dissolution studies of solid dispersions of ketoprofen with PVP K30 and D-mannitol. Saudi Pharm J 2013;21(1):77-84.

15. Khaleel NY, Abdulrasool AA, Ghareeb MM, Hussain SA. Solubility and dissolution improvement of Ketoprofen by solid dispersion in polymer and surfactant using solvent evaporation method. Int J Pharm Pharm Sci 2011;3(4):431-5.

16. Salman S, Ardiansyah A, Nasrul E, Rivai H, Ben ES, Zaini E. Physicochemical characterization of amorphous solid dispersion of ketoprofen-polyvinylpyrorolidone K-30. Int J Pharm Pharm Sci 2014;7(2):209-12. 